\title{
Geodesign: A metametodology in the teaching of the project process in the School of Architecture and Urbanism of the UFPE
}

\section{SIGRADI2018 TECHNOPOLITICAS xxii congresso da sociedade iberoamericana de gráfica digital 22th conference of the iberoamerican society of digital graphics 07|08|09|novembro|2018 iau usp | são carlos | sp br}

\author{
Maria Augusta Rodrigues de Holanda \\ Universidade Federal de Pernambuco |Brazil | mariaaugustarodriguesdeholanda@gmail.com
}

Patrícia Porto Carreiro

Universidade Federal de Pernambuco |Brazil | patricia_carreiro@yahoo.com.br

\begin{abstract}
In 2001, discussions began on the elaboration of a new Pedagogical Project (PPC) for the School of Architecture and Urbanism (CAU) of the Federal University of Pernambuco (UFPE), but only in 2010 a proposal was presented utilizing new didactic-pedagogical concepts and dynamics. After eight years of its implementation, and without a formal evaluation, it was verified the lack of a methodology that manages the teaching process according to the principles formulated in the PPC2010. This article consists of the analysis of the teaching of the CAU /UFPE design process. It also contains a proposal's presentation to update the curricular structure through the meta-methodology of Geodesign. The proposal strives for a better flow of information, integration and contextualization of contents.
\end{abstract}

Keywords: Geodesign; Architectural project; Project teaching.

\section{INTRODUÇÃO \\ O NOVO CONTEXTO PEDAGÓGICO DO CAU/UFPE}

Com o desenvolvimento das cidades, as paisagens urbanas e seus edifícios tornaram-se cada vez mais complexos, exigindo novas estratégias de compreensão, representação e simulação de fenômenos para melhor solucionar as questões espaciais. Esta complexidade se reflete diretamente no processo projetual, e consequentemente, no seu ensino. Diante desta realidade, - Curso de Arquitetura e Urbanismo da Universidade Federal de Pernambuco (CAU/UFPE), ao longo de seus 85 anos de existência, passou por 16 reformas curriculares com o objetivo de atender às novas ofertas e demandas da sociedade.

Apesar do trabalho já realizado, ainda eram necessárias adequações do currículo para cumprir com as novas necessidades da Cidade Contemporânea. Assim, em 2001 foram iniciadas as discussões que embasaram a elaboração do novo Projeto Pedagógico do CAU/UFPE (PPC 2010), e em 2010 este foi aprovado e começou a ser aplicado.

$\mathrm{Na}$ recente proposta foram apresentadas as novas necessidades projetuais: (1) Interpretação das informações de forma/conceito; (2) Construção de um partido integrado; (3) Emprego de várias tecnologias; (4) Variedade de produtos manufaturados e a articulação entre eles; (5) Reflexão sobre os processos sociais, econômicos e políticos que exigem sensibilidade (Amorim, Leite, Gonçalves, Portocarreiro, 2010).

Para trabalhar com estes elementos o novo currículo do curso de Arquitetura e Urbanismo da UFPE apresentou os princípios pedagógicos: (1) Indissociabilidade do problema projetual urbano/ paisagem/ edifício; Interdisciplinaridade; e (3) Aprendizagem baseada problemas reais; (Amorim, Leite, Gonçalves, Portocarreiro, 2010), detalhados a seguir, de forma a propiciar que os arquitetos possam resolver problemas espaciais atuais mais adequadamente.

A versão final aprovada apresentou uma estrutura curricular composta pelos sistemas: (1) Curricular responsável pela organização das cadeiras e fluxo dos conteúdos, (2) Pedagógico - responsável pela aplicação A estruturação desses conhecimentos está disposta em torno da atividade de projeto integrado e de suas especificações: Projeto de edificações, Projeto urbano e Projeto de paisagismo (Amorim, Loureiro, Leite, 2002).

As disciplinas ofertadas pelo curso foram classificadas em três categorias:

1. Integrativas - disciplinas com função de síntese dos conhecimentos teórico-práticos ensinados no curso, as disciplinas de Projeto, e suas especificações, estão nesta categoria;

2. Instrumentais - matérias que ensinam a instrumentação, utilização e aplicação de técnicas ou ferramentas necessárias para auxiliar no processo projetual integrado, nas tomadas de decisão e representação, como as disciplinas de Geometria Gráfica, Conforto Ambiental e Informática Aplicada;

3. Conceituais - as disciplinas desta categoria são compostas por conteúdos teóricos e têm a função de introduzir e discutir os conceitos, princípios, teorias e ideias relacionadas ao ato projetual, disciplinas como 
História e Teoria da Arquitetura compõem este grupo (Amorim, Leite, Gonçalves, Portocarreiro, 2014). (Figura 1)

\begin{tabular}{|c|c|c|}
\hline INTEGRAÇÃO & INSTRUMENTAL & CONCEITUAL \\
\hline $\begin{array}{l}\text { Projeto de } \\
\text { Arquitetura } \\
\text { Projeto de } \\
\text { Urbanismo e } \\
\text { Paisagismo } \\
\text { Planejamento } \\
\text { Urbano e Regional } \\
\text { (PUR) }\end{array}$ & $\begin{array}{c}\text { Geometria 2D } \\
\text { Geometria 3D } \\
\text { Técnicas de } \\
\text { Retrospectiva } \\
\text { Tectônica } \\
\text { Conforto Ambiental } \\
\text { Informática Aplicada } \\
\text { à Arquitetura e } \\
\text { Urbanismo (InfoAU) } \\
\text { Topografia } \\
\text { Infraestruturas }\end{array}$ & $\begin{array}{c}\text { Estética } \\
\text { História da Arte } \\
\text { Estudos } \\
\text { Socioeconômicos e } \\
\text { Ambientais (ESEA) } \\
\text { História da } \\
\text { Arquitetura e } \\
\text { Urbanismo } \\
\text { Teoria da } \\
\text { Arquitetura e } \\
\text { Urbanismo }\end{array}$ \\
\hline
\end{tabular}

Figura 1: Quadro com as disciplinas ofertadas pelo curso e suas categorias.Fonte: Elaborada pelo autor.

Ainda de acordo com o PPC 2010, o curso deve promover uma leitura e compreensão crítica da cidade sobre os assuntos relacionados à arquitetura, urbanismo e paisagismo. Para oferecer esta formação o PPC 2010 se fundamenta em três diretrizes:

1. Indissociabilidade do problema projetual da cidade/paisagem/edifício - Partindo do princípio que os problemas da cidade interferem diretamente na forma de viver da sociedade, esta diretriz pretende integrar a educação acadêmica de dentro da sala com as experiências da cidade, tomando como indissociável os problemas públicos (cidade) e os privados (edifícios), tentando resolver as questões espaciais de forma integrada, sabendo-se que uma reflete diretamente na outra;

2. Interdisciplinaridade - Para reverter o caráter compartimentalizado da formação acadêmica do curso de arquitetura, busca-se a interdisciplinaridade a partir do processo de projeto integrado a ser desenvolvido no ano;

3. Aprendizagem baseada em problemas - Integração da educação formal da academia com a vivência da cidade, tendo como ponto inicial os problemas urbanos, paisagísticos e arquitetônicos presentes na cidade. Desta forma os alunos devem trabalhar e desenvolver projetos baseados em problemas reais, ligados de forma direta com a cultura, população e realidade de onde atuarão.

"A atividade de projeto, especificidade e diferencial do profissional arquiteto e urbanista, é entendida como a capacitação para organizar os espaços para as atividades humanas. A concepção do ensino do projeto abrange a definição conceitual do problema e sua resolução técnica - sua construtividade." (Amorim, Leite, Gonçalves, Portocarreiro, 2014, p. 216)
Desta forma está composta a nova estrutura curricular do PPC 2010. O referido projeto integrado, desenvolvido durante o ano letivo, consiste na união dos conhecimentos das disciplinas instrumentais e conceituais como fundamentação à disciplina de Projeto de Arquitetura, Urbanismo e Paisagismo. Este fluxo de informações é repetido nos diferentes semestres de acordo com as escalas de intervenção do tema estudado no ano. Os temas abordados anualmente são respectivamente: Requalificação, Renovação, Expansão e Conservação.

Durante o período letivo estão alocados momentos para apresentação das intenções e propostas de projeto para o acompanhamento do seu andamento:

1. CAPO - O primeiro contato com a proposta do ano, este introduz o tema do ano letivo e a área de estudo que receberá a intervenção;

2. SEGNO - Este segundo momento é utilizado para apresentar as propostas e estimular a discussão coletiva, nesta disciplina além de apresentados os projetos é realizado o acompanhamento do desenvolvimento do projeto. A proposta do Segno é que este permita momentos de integração onde as disciplinas conceituais e instrumentais são avaliadas juntamente ao processo projetual;

3. CODA - Apresentação final do semestre com o projeto finalizado e avaliação das propostas (Amorim, Leite, Gonçalves, Portocarreiro, 2010).

Assim, ao longo do curso o aluno desenvolve projetos em sua completude, desde o conceito até a forma de execução dos seus elementos.

A ideia final do currículo apresenta novos conceitos, dinâmicas e propostas didático-pedagógicas para integrar os conteúdos teórico-práticos inerentes ao ensino do processo projetual de arquitetura, urbanismo e paisagismo na estrutura curricular do Curso de Arquitetura da UFPE (Amorim, Leite, Gonçalves, Portocarreiro, 2010).

\section{O PROBLEMA}

Apesar de já passados oito anos da sua instituição, ainda não houve uma avaliação formal do PPC 2010, mas é notório pelas discussões em Colegiado e de planejamento dos semestres letivos, entre alunos e professores, que o curso apresenta problemas na execução de seus princípios norteadores (Rêgo e Portocarreiro, 2015).

A premissa deste trabalho é que falta uma metodologia conjunta e integrativa que possibilite o planejamento dos conteúdos e conduza o trabalho colaborativo entre os responsáveis pelas disciplinas do curso. A falta de organização, do próprio processo de ensino projetual, resulta em ementas, ferramenta utilizada para guiar o andamento da disciplina, abrangentes, sem apresentar o resultado final esperado para disciplina, que auxilie na cadeira de Projeto, como descrito no PPC.

A ausência da sistematização para inserção e encadeamento do conteúdo das ementas também repercute no planejamento individual, a cada semestre, de um plano de ensino de cada disciplina. Este planejamento individual tem como consequência a falta de visão do todo: da interligação entre estes conteúdos; de que fase 
do processo projetual eles contemplam e são contemplados e como conduzir o trabalho coletivo e colaborativo deste processo.

Em suma, é evidenciada a necessidade de uma metodologia para coordenar o próprio método de ensino do processo projetual, ou melhor, as informações e etapas da metodologia projetual e, mais especificamente, o fluxo dos conteúdos de cada disciplina, dos anos e de todo o Curso dentro da estrutura curricular, além de conduzir o trabalho colaborativo entre as partes. Propõe-se que uma metametodologia, processo responsável por sistematizar uma metodologia, conjunta integrativa para concretizar as propostas presentes no PPC/2010.

\section{O GEODESIGN COMO METAMEDODOLOGIA DE ENSINO DO PROCESSO PROJETUAL}

O Geodesign foi escolhido como uma proposta de metametodologia para guiar a sistematização e comunicação das etapas do projeto de forma colaborativa. No livro "Um Framework para o Geodesign" escrito por Carl Steinitz, são expostos os princípios do Geodesign como uma ferramenta para guiar o projeto integrado e também apresenta estudos de caso com o trabalho colaborativo entre diferentes profissões na área de projeto e ciências geográficas. Esses projetos variam de escala, publico, estratégias e objetivos, reiterando a aplicabilidade do geodesign.

"O geodesign é aplicável em qualquer e em todo lugar, mas raramente da mesma forma." (Steinitz, 2012, p. 19)

"Existe grande variação na forma como as pessoas projetam [...], não existe um único método ou caminho para o Geodesign." (Steinitz, 2012, p. 3)

Existem três elementos importantes apresentados pelo Geodesign a ser considerados para a elaboração de um projeto: (1) a Geografia - é a área de estudo, suas características; (2) Escala - elemento que permite a apreensão da área de intervenção e as informações que serão apresentadas e (3) Dimensão - está relacionado com o impacto do projeto (Steinitz, 2012). Estes elementos serão tratados pela equipe de Geodesign, formada por diferentes agentes: Profissionais de projeto, Tecnólogos, Cientistas da Geografia e Pessoas do lugar, para a elaboração de um projeto com abordagem integrativa.

É importante ressaltar que o Geodesign não é uma metodologia projetual a ser seguida como passo a passo, não existe um processo de Geodesign, sua metodologia e abordagem podem ser aplicados em projetos de diferentes enfoques. Como consequência da vasta abordagem do Geodesign, todo este processo deve ser organizado para formular as questões e definir os métodos de intervenção mais apropriados para resolvêlas.

\section{A PROPOSTA}

O Geodesign, sendo um campo de pesquisa emergente na área de planejamento espacial, se destaca por sua abordagem essencialmente interdisciplinar, permitindo uma maior integração entre as diversas áreas envolvidas no processo de planejamento. Diante disso, foi verificada a possibilidade de adequação das etapas processuais e de modelos recomendados pelo Geodesign aplicando-os no processo projetual de ensino das disciplinas ofertadas no referido Curso. O Geodesign foi escolhido como opção por ser específico para processos projetuais espaciais e por trabalhar de forma integrada com diferentes áreas de atuação e conhecimento. Esta ferramenta também possibilita rápida difusão no ensino e na prática projetual.

"Geodesign é um método de projeto e planejamento que acopla perfeitamente a criação de propostas de projeto com simulações de impacto informadas pelo contexto geográfico, pelo pensamento sistêmico e pela tecnologia digital" (Flaxman, 2010).

Diante do problema enfrentado pelo CAU/UFPE, é investigada a adoção de uma metodologia para a readequação da estrutura curricular existente a uma que garanta o alinhamento dos princípios pedagógicos do curso com os princípios, etapas, modelos e métodos do Geodesign. Esta ferramenta auxilia o processo projetual, por meio da integração do conteúdo das disciplinas, administração dos fluxos de informação e dinamização do trabalho colaborativo, otimizando a base teóricometodológica para as cadeiras integrativas de Projeto.

Como essa proposta pretende-se verificar, de forma ampla, se o Geodesign pode aperfeiçoar e colaborar com a sedimentação das diretrizes teórico-metodológicas do PPC2010/CAU/UFPE (Portocarreiro e Rêgo, 2014); além de quais, quando e onde as tecnologias digitais devem promover esta abordagem integrativa (Portocarreiro, 2015).

O Geodesign foi escolhido como metametodologia a ser testada por ser proposta como um processo colaborativo, baseado em um conjunto de questões e métodos interrelacionados que trabalham sistematicamente para resolução de problemas espaciais em diferentes escalas, dimensões e áreas de conhecimento (Steinitz, 2012), assemelhando-se aos princípios e dinâmicas norteadores do PPC2010.

Esta proposição será elaborada por meio de orientações para auxiliar a integração, contextualização e trabalho coletivo entre as cadeiras que compõem os módulos do curso, buscando maior inserção e espacialização dos temas abordados.

Baseado no livro Um Framework para o Geodesign de Carl Steinitz e o artigo Novas Práticas Pedagógicas da Matéria de Informática Aplicada à Arquitetura, Urbanismo e Paisagismo: Experimentações dentro do Novo Currículo do Curso de Arquitetura e Urbanismo/UFPE serão propostas diretrizes para solução dos problemas de integração de conteúdos enfrentados no curso. Além disso, pretende-se investir na aproximação da metodologia de projeto com o processo de Geodesign como uma possível metodologia de ensino aplicada ao CAU/UFPE que permita a integração destas disciplinas com a cadeira de projeto. Para isso foi proposta uma metodologia de estudo que identificasse estes pontos comuns ao PPC 2010 e o Geodesign.

\section{METODOLOGIA}

1. Investigar os três principais princípios pedagógicos do PPC2010 (indissociabilidade do problema projetual da cidade/paisagem/edifício, interdisciplinaridade e aprendizagem baseada em problemas.); 
2. Identificar as falhas na aplicação das diretrizes do PPC2010 no planejamento do curso;

3. Investigar as possíveis metametodologias para orientar o processo projetual e entre elas o Geodesign;

4. Investigar como as características e etapas dos Geodesign podem dar maior aporte aos princípios didáticos pedagógicos do PPC2010;

5. Analisar exemplos de abordagem do problema de forma integrada, com diferentes escalas e como as ferramentas podem auxiliar no processo projetual;

6. Propor uma metodologia para o PPC2010 através da implantação da ferramenta do Geodesign/ Metodologia conjunta para planejamento das cadeiras, seguindo o princípio da indissociabilidade;

7. Elaborar uma proposta para estudo de caso para aplicação do Geodesign no $3^{\circ}$ período do curso de Arquitetura e Urbanismo da UFPE;

8. Propor diretrizes para aprimorar o processo de ensino e permitir melhorias na integração dos conteúdos;

9. Reorganizar e classificar as cadeiras, baseada nas escalas de intervenção, conteúdos abordados e sua relação com os princípios do Geodesign.

\section{ESTUDO DE CASO}

Em 1967 foi realizada uma experiência com o uso do Geodesign em atividades da universidade. Esse exercício foi desenvolvido em uma oficina multidisciplinar onde os alunos fariam propostas para um determinado local que, em consequência do seu crescimento, passou a demandar novas áreas industriais, residenciais, comerciais, de lazer e áreas livres. A intervenção foi realizada em uma região de Boston e, além de um projeto de expansão urbana, a atividade consistiu em: Analisar os conflitos entre o crescimento urbano e a vulnerabilidade da paisagem; Organização de um SIG para representação da área; e avaliação dos impactos financeiros, paisagísticos, políticos e naturais. Nesta oficina também foram desenvolvidos diagramas de uso do solo, áreas de interesse, recursos da área e avaliação das vulnerabilidades para avaliar os impactos das propostas. (Steinitz, 2012)

Outro experimento baseado na multidisciplinaridade foi realizado em 2015 por meio de uma experiência didáticopedagógica no curso de Arquitetura e Urbanismo da UFPE. Esta prática foi ministrada pela cadeira de Informática aplicada à Arquitetura e Urbanismo (InfoAU) e teve como objetivo a criação colaborativa de modelos multiescalas integrados. A atividade desenvolvida na disciplina consistiu na elaboração de mapas temáticos georreferenciados e modelagens 3D produzidas pelos alunos. Esta atividade reuniu informações das demais cadeiras do período em uma base única e de fácil acesso (Portocarreiro, Rêgo, Feitosa, Holanda, Balbino, Martins, 2015).

Compartilhando ideias da experiência de Boston e visando ampliar esta experimentação de InfoAU, serão analisadas ferramentas que viabilizem a proposta da aplicação do
Geodesign como metametodologia, e dando continuidade às propostas do projeto integrado.

Para atingir tal objetivo, foi elaborado um estudo de caso que utilizou o Geodesign como arcabouço teóricometodológico para organizar os princípios pedagógicos do PPC2010 por meio da sistematização dos conteúdos das disciplinas e dos fluxos destes. Para esta experiência foi analisado o calendário letivo do $3^{\circ}$ período de 2018.2. Essa organização será baseada nas Seis Questões do Framework para o Geodesign, apresentadas no livro Um Framework para o Geodesign de Carl Steinitz.

As seis questões levantam pontos como a descrição da área, seu funcionamento, quais alterações são propostas, seus impactos e mudanças previstas.

Em seu livro, o escritor Carl Steinitz explica que todo projeto pode e deve ser organizado para responder a essas seis questões base para o framework do Geodesign e além do questionamento o também são apresentados quais modelos podem oferecer as respostas (Figura 2).

\begin{tabular}{|c|c|}
\hline PERGUNTAS & MODELOS \\
\hline $\begin{array}{l}\text { Como a área de estudo } \\
\text { deveria ser descrita? }\end{array}$ & Modelo de Representação \\
\hline $\begin{array}{c}\text { Como a área de estudo } \\
\text { funciona? }\end{array}$ & Modelo de Processo \\
\hline $\begin{array}{l}\text { A área de estudo atual está } \\
\text { funcionando bem? }\end{array}$ & Modelo de Avaliação \\
\hline $\begin{array}{c}\text { Como a área de estudo pode } \\
\text { ser alterada? }\end{array}$ & Modelo de Mudança \\
\hline $\begin{array}{c}\text { Que diferenças as mudanças } \\
\text { podem causar? }\end{array}$ & Modelo de Impacto \\
\hline $\begin{array}{c}\text { Como a área de estudo pode } \\
\text { ser mudada? }\end{array}$ & Modelo de Decisão \\
\hline
\end{tabular}

Figura 2: Quadro com as perguntas do framework do Geodesign e os modelos correspondentes. Fonte: Elaborada pelo autor

A análise consiste em: (1) Identificar, dentre os módulos de projeto, em qual momento os alunos têm acesso às informações necessárias para responder às questões do framework do Geodesign; (2) Levantar os problemas encontrados na organização das disciplinas; e (3) Elaborar uma proposta de como solucionar a questão da disposição das cadeiras para atender aos questionamentos levantados pelo Geodesign.

Para a efetivação deste estudo será proposta, juntamente com os professores responsáveis pela disciplina de projeto, a organização das etapas de projeto segundo os modelos do Geodesign.

\section{RESULTADOS}

Ao analisar as ementas das disciplinas do curso em questão, nota-se que estas não estimulam a integração entre seus resultados, como também não lançam qual produto é esperado ao final de cada uma delas, deixando 
assim seus conteúdos sem um direcionamento aos objetivos do semestre.

Este problema também resulta na dificuldade de execução, integração e espacialização dos conceitos abordados pelas disciplinas. Tal fato limita, ou até impede, o aporte das disciplinas conceituais e instrumentais à disciplina integrativa de Projeto.

Diante deste panorama, a intenção da aplicação do Geodesign propõe resolver estas questões por ordenar os conteúdos e os produtos entre as disciplinas. Como resultado das análises iniciais realizadas durante uma disciplina eletiva (TE-Info 1 em 2018.2) do curso, que fomentou esta pesquisa, verificou-se que o fluxo de informações do conjunto de disciplinas podem ser (re)orientados segundo o Geodesign permitindo maior integração dos conteúdos teórico-práticos e melhorando o aporte conceitual e instrumental à disciplina de Projeto.

Com o estudo de caso que será aplicado e analisado em agosto, início do semestre 2018.2, será analisada e verificada as hipóteses levantadas sobre a aplicação efetiva da abordagem do Geodesign como metametodologia que podem ser trazidas para o PPC 2010. Neste sentido, foram elaborados:

1) Um diagrama que representa a organização das disciplinas ao longo do período (Figura 3). Com a disposição das disciplinas já definidas para 2018.2 foi identificada a primeira hipótese: Qual a importância de se respeitar os módulos de disciplinas instrumentais ou conceituais para servirem efetivamente como aporte à disciplina de Projeto? Pois, verifica-se que as disciplinas prolongam-se além do proposto pelo PPC 2010, ou seja, a alocação das disciplinas deveria priorizar o seu término antes dos módulos de projeto que servirão de aporte instrumental ou conceitual.

2) Com a disposição do período 2018.2, também é possível identificar em quais módulos de projeto os alunos teriam conhecimento suficiente para elaborar as respostas para as perguntas do framework, estas questões devem ser apresentadas para os alunos refletirem enquanto desenvolvem o projeto e as respostas estarão expressas nos projetos apresentados no Segno e Coda (Figura 3).

Assim, formula-se a segunda hipótese: O curso oferece os conhecimentos necessários para a elaboração das respostas para o framework? Pois, devido ao problema do prolongamento das disciplinas ou desrespeito aos módulos inicialmente planejados pelo PPC2010, as perguntas começam a ser respondidas no meio do período, resultando em pouco tempo elaboração de propostas bem construídas.

Após a aplicação deste estudo de caso, com dados mais específicos para solucionar os problemas encontrados pretende-se formular uma proposta de uma nova organização das disciplinas ao longo do período, em que estas sejam separadas em módulos baseados nas perguntas do framework do Geodesign (Figura 3). Cada módulo de projeto responderia a determinadas questões, sendo resultado de conhecimentos adquiridos de outros módulos anteriores, como a questão número 5 que é respondida pelo modelo de impacto, resultante dos conteúdos abordados ao longo do semestre.

Em paralelo os alunos também respondem as Três Iterações do Framework do Geodesign, apresentado por Carl Steinitz no livro "Um Framework para o Geodesign". Estas perguntas são responsáveis por solucionar questões projetuais como: Por que, Como, O que, Onde e Quando intervir.

Estas questões são respondidas pelas análises das respostas das Seis questões do Framework. Ao utilizar essa metodologia no período, a disciplina de projeto seria responsável por fomentar as propostas com aporte das outras disciplinas que respondem as iterações no Segno e Coda. 


\section{DISPOSIÇÃO DAS DISCIPLINAS DO $3^{\circ}$ PERIOODO \\ 2018.2}

ATUAL

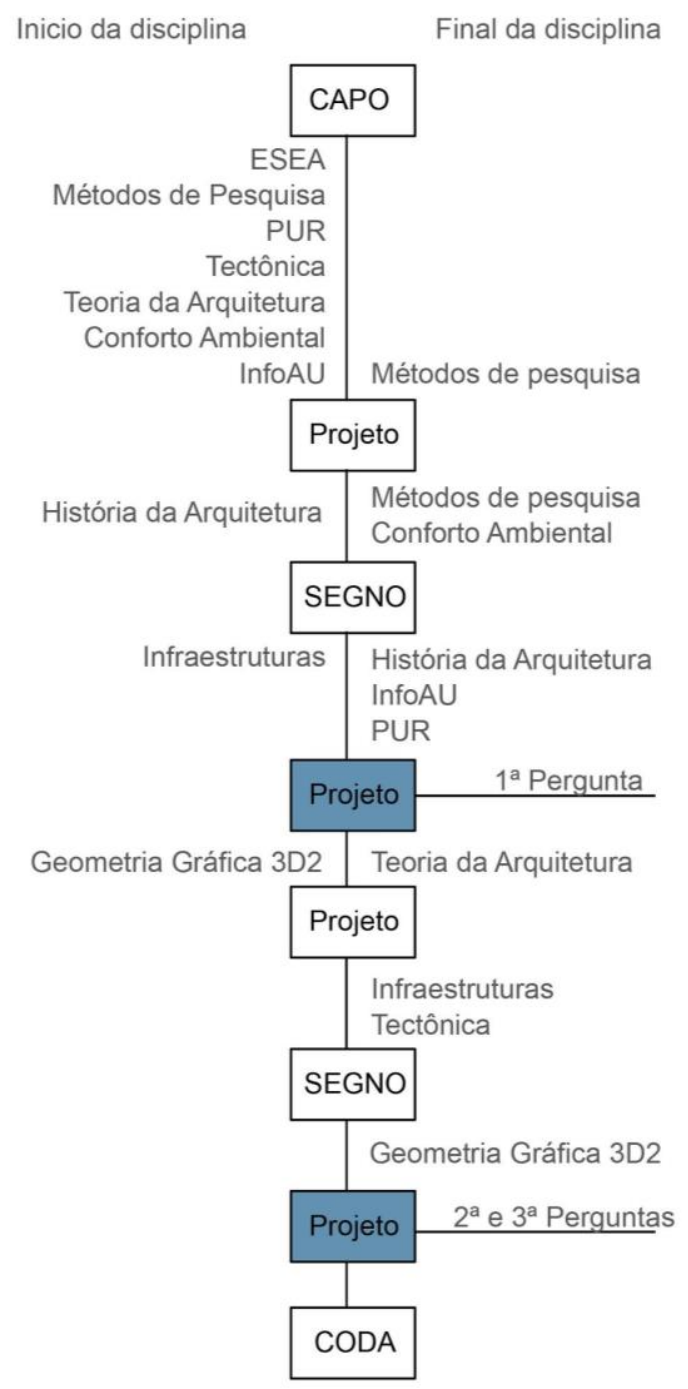

PROPOSTA

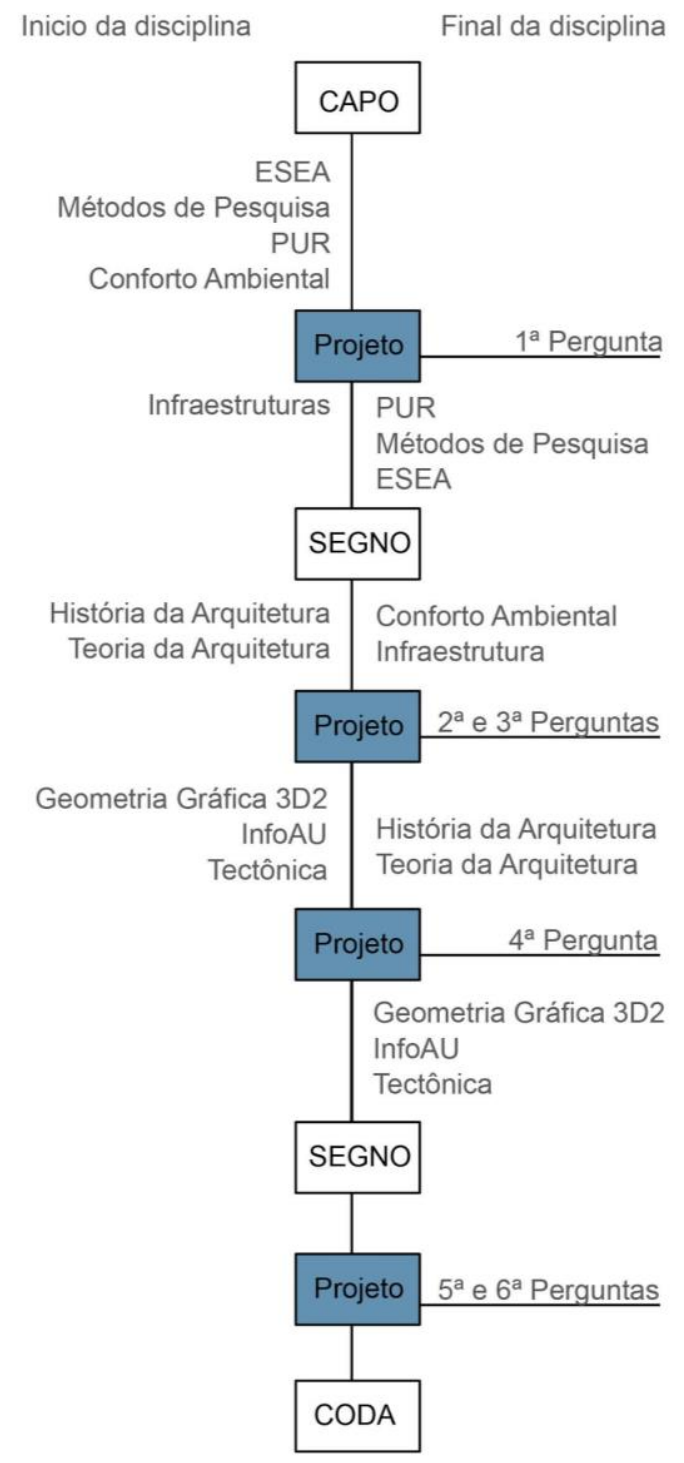

Figura 3: Diagrama que representa a disposição das cadeiras do curso de Arquitetura e Urbanismo da UFPE, ofertadas para o terceiro período de 2018.2, com a indicação do início e encerramento dessas. No diagrama da esquerda está a organização atual e o diagrama da direita apresenta a proposta elaborada com a reorganização das disciplinas seguindo a metodologia escolhida. Fonte: Elaborada pelo autor

No primeiro Segno o aluno responde a primeira iteração: POR QUE a área deve ser alterada, por meio dos conhecimentos adquiridos até o momento e elaborando uma evolução no pensamento do processo.

O segundo Segno já é apresentado um estudo inicial de projeto e diretrizes para a área de intervenção que expresse COMO a área deve ser alterada. Agora as questões do framework são resolvidas ao mesmo tempo em que é pensado como a área deve ser alterada e como ela irá funcionar.
No Coda será respondida a terceira iteração: O QUE, ONDE e QUANDO, em alguns projetos não será necessário cobrar o QUANDO. No momento do Coda será apresentado o projeto final e a área a ser detalhada no período seguinte. O estudo de caso servirá para verificar e aprofundar formas de aplicação do Geodesign no curso.

Durante as pesquisas preliminares feitas em TE-Info1 foram levantadas outras formas de emprego do Geodesign no PPC2010:

1. A escala da intervenção - $O$ Geodesign pode ser utilizado em projetos de diferentes escalas: Local, 
Regional ou Global. Cada escala de projeto requer uma abordagem diferente, conhecimentos específicos e práticas profissionais, além dos diferentes objetivos projetuais e limites territoriais. Diante disso, verificou-se a possibilidade da utilização do Geodesign: (1) Nos períodos ímpares - são realizados projetos de grande escala, abordado temas em níveis regionais, como Requalificação, Renovação, Expansão e Conservação Urbana e (2) Períodos pares - projetos de menor escala a nível local, baseados nos projetos do período anterior.

"É importante separar as escalas de intervenção - toda atividade de Geodesign é necessariamente composta por decisões a serem feitas em cada estágio do projeto. A medida que o tamanho de um projeto de Geodesign aumenta, as decisões centralizadas dominarão as descentralizadas." (Steinitz, 2012 p.22)

2. A associação de conhecimentos e posturas específicas - O Geodesign apresenta quatro campos de informação que contribuem com informações para a tomada de decisão no processo projetual: (1) As pessoas do lugar; (2) Profissionais de projeto - arquitetos, urbanistas, paisagistas, engenheiros civis; (3) Ciências geográficas geógrafos, profissionais da hidrologia, economistas, sociólogos; (4) Tecnologias da informação. Os participantes destas áreas contribuem com informações específicas em determinadas etapas projetuais. Diante disso, percebeu-se a possibilidade de utilização dessas quatro áreas do Geodesign como guia para reorganização do fluxo de informações e a identificação de quais disciplinas podem contribuir com conhecimentos relativos ao projeto referido no ano letivo. Baseado na classificação das cadeiras (instrumental, integração e conceitual) e no princípio da aprendizagem baseada em problemas reais, nota-se a possibilidade dessa aproximação dos ideais do curso com a proposta do Geodesign, sendo possível enquadrar as propostas do PPC 2010 na organização do Geodesign (Figura 4).

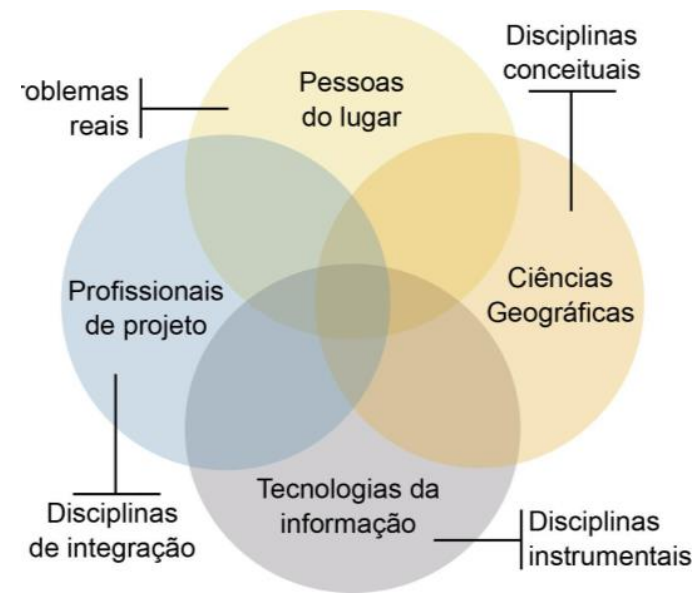

Figura 4: Imagem com as áreas de conhecimento do Geodesign juntamente com os princípios do curso de arquitetura, mostrando a união das informações. Fonte: Elaborada pelo autor

\section{DISCUSSÃO}

É de grande importância a proposta do PPC 2010 de trazer problemas reais para trabalhar no ensino do processo projetual do curso e propor a integração de conhecimentos de diferentes áreas. Apesar de finalizada a proposta do PPC 2010 há oito anos, falta uma metodologia que unisse proposta, curso e fluxo de informação, ou seja, que oriente o próprio processo do ensino projetual.

Diante disso o Geodesign é pensado como solução por orientar como organizar essa colaboração entre os fatores que contribuem na resolução do problema espacial abordado na disciplina de Projeto de Arquitetura, Urbanismo e Paisagismo. Assim,buscou-se identificar onde 0 Geodesign colabora com os Princípios Pedagógicos do CAU/UFPE como uma proposta de metodologia de projeto interdisciplinar e multi escala.

O Geodesign, como forma de organização dos conteúdos, sistematiza o processo de planejamento urbano e arquitetônico, abrangendo da criação de propostas até as simulações de seus impactos em um contexto geográfico pelo uso das tecnologias digitais, além disso, trabalha com diferentes profissionais em diferentes escalas de intervenção de forma organizada, assemelhando-se a proposição do PPC 2010. Dessa forma, foi percebido seu potencial de aplicação como uma metametodologia capaz de organizar e guiar os princípios propostos pelo currículo novo ao curso de Arquitetura.

Após as análises foi verificada a importância da organização dos conteúdos das ementas, para que assim os objetivos das disciplinas sejam expostos de forma clara e bem definidos. Ao especificar como cada cadeira pode acrescentar no processo projetual o docente pode se inteirar melhor a respeito do projeto do período. Outra vantagem é a liberdade de metodologia de ensino atribuída ao professor das cadeiras, sendo que ao final da disciplina os alunos devem ter fundamentos metodológicos suficientes para responder às perguntas do framework do Geodesign e seguir com o projeto em questão.

Outro ponto que o Geodesign acrescenta para o processo de projeto é a participação da população na tomada de decisão, este elemento é previsto no PPC 2010 mas não está expresso como proposta em nenhuma das ementas das cadeiras do curso. Assim, o Geodesign pode auxiliar neste momento como ferramenta para integrar a população no processo de projeto.

A contribuição de diferentes conhecimentos e posturas no processo projetual é resultado da união dos conhecimentos que auxilia na tomada de decisão, tendo em vista que problemas reais não abrangem apenas um conteúdo. Neste ponto a interdisciplinaridade e integridade puderam ser reafirmadas pela proposta do PPC 2010 do Projeto baseado em problemas reais.

\section{REFERÊNCIAS}

Amorim, L., Leite, M. J., Gonçalves, G. M., Porto Carreiro, P. (2010). Projeto Pedagógico do Curso de Arquitetura e Urbanismo da UFPE - Diretrizes da Reforma Curricular 2010. Recife: CCEPE UFPE

Amorim, L. M. E., Britto Leite, M. J., Gonçalves, G., Porto Carreiro, P. (2014). Conceito, instrumento, integração: postulados pedagógicos do CAU/UFPE. XXXIII ENSEA Encontro Nacional sobre Ensino de Arquitetura e Urbanismo, 210-223. 
Araújo, U. F., Sastre, G.(2009). Aprendizagem baseada em problemas no ensino superior. São Paulo: Summus.

Fazenda, I. C. A. (2008). O que é a Interdisciplinaridade?. São Paulo: Cortez.

Flaxman, M., Steinitz, C., Faris, M., Canfield, T., Vargas-Moreno, J. C. (2010). Alternative Futures for the Telluride Region, Colorado. Telluride Foundation.

Fonseca, B. M. (2016). Geodesign: Conceitos e Arcabouço Metodológico. Tecnologias de Geoinformação para representar e planejar o território urbano, 1ed, v. 1, p. 196215.

Porto Carreiro, P., Rêgo, R. M., Feitosa, A., Holanda, M. A., Balbino, M., Martins, M. A. (2015, Novembro). Tecnologias de Gestão, Colaboração e Comunicação no apoio ao Ensino do Processo Projetual para a Construção de Modelos Multiescalas Integrados. VII Encontro de Tecnologia de Informação e Comunicação na Construção - Edificações, Infra-estrutura e Cidade: Do BIM ao CIM, vol.2, num.2. Retrieved from: http://www. proceedings.blucher.com.br/article-details/tecnologias-degesto-colaborao-e-comunicao-no-apoio-ao-ensino-doprocesso-projetual-para-construo-de-modelos-multiescalasintegrados-20564.
Porto Carreiro, P., Rêgo, R. M. (2014). Novas práticas pedagógicas da matéria de Informática aplicada à Arquitetura, Urbanismo e Paisagismo: experimentações dentro do Novo Currículo do Curso de Arquitetura e Urbanismo/UFPE. In: Anais do XXXIII ENSEA Encontro Nacional sobre Ensino de Arquitetura e Urbanismo. v. 1. 224-242.

Rêgo, R., Carreiro, P. P. (2015) Adoção de tecnologias de informação e comunicação no curso de arquitetura e urbanismo da UFPE: Buscando uma proposta para potencializar a interdisciplinaridade. Projeto de Pesquisa UFPE.

Silva, S., Carreiro, P. P. (2015). Gestão do processo projetual arquitetônico: conceitos, metodologias e ferramentas para viabilização das etapas projetuais. Encontro Brasileiro de Tecnologia de Informação e Comunicação na Construção, 7.Porto Alegre: ANTAC.

Steinitz, C. (2012). Um Framework para o Geodesign: Alterando a Geografia através do Design. 1. ed. Estados Unidos da América: Esri.

Thiesen, J. S. (2008, setembro/dezembro). A interdisciplinaridade como um movimento articulador no processo ensino aprendizagem. Revista Brasileira de Educação.[online]. vol.13, n.39, pp. 545-554. 